\title{
A propeptide toolbox for secretion optimization of Flavobacterium meningosepticum endopeptidase in Lactococcus lactis
}

Pei Yu Lim', Lee Ling Tan², Dave Siak-Wei OW ${ }^{1^{*}} \mathbb{D}$ and Fong T. Wong ${ }^{2^{*}}$

\begin{abstract}
Background: Lactic acid bacteria are a family of "generally regarded as safe" organisms traditionally used for food fermentation. In recent years, they have started to emerge as potential chassis for heterologous protein production. And more recently, due to their beneficial properties in the gut, they have been examined as potential candidates for mucosal delivery vectors, especially for acid-sensitive enzymes. One such application would be the delivery of glutendigesting endopeptidases for the treatment of celiac disease. To facilitate these applications, an efficient recombinant protein expression toolbox is required, especially for recombinant protein secretion. While current tools for enhancing protein secretion consist mainly of signal peptides, secretion propeptides have also been observed to play a crucial role for protein secretion and improved yields.
\end{abstract}

Results: To expand the propeptide library for secretion optimization, we have mined and characterized three naturally occurring propeptides from the sequenced genomes of 109 Lactococcus species. These newly-mined propeptides were introduced after the N-terminal USP45 secretion signal to characterize and compare their effects on the secretion of Escherichia coli thioredoxin (TRX) and Flavobacterium meningosepticum prolyl endopeptidase (Fm PEP) in Lactococcus lactis NZ9000. All three propeptides, along with the positive control LEISSTCDA, improved volumetric secretion yields by 1.4-2.3-folds. However, enhancement of secretion yield is dependent on protein of interest. For TRX, the optimal combination of USP45 signal peptide and LEISSTCDA produced a 2.3-fold increase in secretion yields. Whilst for Fm PEP, propeptide 1 with USP45 signal peptide improved volumetric secretion yields by 2.2-fold compared to a 1.4-fold increase by LEISSTCDA. Similar trends in Fm PEP activity and protein yield also demonstrated minimal effect of the negative charged propeptides on PEP activity and thus folding.

Conclusions: Overall, we have characterized three new propeptides for use in L. lactis secretion optimization. From success of these propeptides for improvement of secretion yields, we anticipate this collection to be valuable to heterologous protein secretion optimisation in lactic acid bacteria. We have also demonstrated for the first time, secretion of Fm PEP in L. lactis for potential use as a therapy agent in celiac disease.

Keywords: Flavobacterium meningosepticum prolyl endopeptidase, Lactic acid bacteria, Lactococcus lactis, Secretion propeptide, Recombinant protein expression

\footnotetext{
${ }^{*}$ Correspondence: dave_ow@bti.a-star.edu.sg; wongft@bmsi.a-star.edu.

$\mathrm{sg}$

${ }^{1}$ Microbial Cell Group, Bioprocessing Technology Institute, Agency

for Science, Technology and Research (A*STAR), 20 Biopolis Way, \#06-01

Centros, Singapore 138668, Singapore

${ }^{2}$ Molecular Engineering Lab, Biomedical Sciences Institutes, A*STAR, 61

Biopolis Drive, Singapore 138673, Singapore
} 


\section{Background}

Lactic acid bacteria (LAB) are a promising family of food-grade organisms for heterologous protein production due to its Generally Regarded as Safe (GRAS) status. Representative genera of LAB include Lactobacillus, Bifidobacterium, Lactococcus, Aerococcus, Leuconostoc, Oenococcus and Pediococcus [1]. Traditionally, LAB were utilized in food as starter cultures for fermentation and as probiotics [2]. Studies of LAB and host interactions have also associated LAB directly with cellular activities of the gut, such as pathogen control, immunostimulation and maintaining a healthy microflora $[3,4]$. Combined with their traditional roles in food fermentation, beneficial gut properties, and resistance to harsh gut conditions, additional advantages such as LAB's ability to secrete recombinant proteins while possessing fewer proteases, compared to traditional workhorses, such as Escherichia coli and Bacillus subtilis, have made them attractive targets for recombinant cell factories and live vectors for delivery of therapeutic molecules in the gut [5].

Celiac disease is an inflammatory autoimmune disorder of the small intestine arising from intolerance to gluten in food. Traditional treatment of celiac disease mainly consists of dietary restrictions, however even traces of gluten contaminants can be immunogenic and result in detrimental consequences over time. A recent promising development of oral therapy for celiac disease, using food grade prolyl endopeptidase (PEP) to break down contaminant gluten, have sparked interest into exploring non-dietary alternatives using mucosal enzyme delivery vectors, such as LAB. Delivery of digestive enzymes to breakdown gluten have been investigated for predigested gluten and in situ gastrointestinal lumen treatment. In the latter, oral therapy using combination of acid-resistant food grade digestive enzymes have recently entered phase III trials for celiac disease treatment [6]. However, for acid sensitive PEPs, delivery efficiency and the ability of delivery vectors to survive through the gastrointestinal tract would have to be examined and optimized. Previously, secretion of Myxococcus xanthus prolyl endopeptidase (Mx PEP) has been explored successfully in Lactobacillus casei [7] for the digestion of the 33-mer gliadin-derived epitopes in an in vitro small intestine model. However, in an oral administration study in rats, Mx PEP did not shown PEP-specific cleavage compared to the Flavobacterium meningosepticum prolyl endopeptidase (Fm PEP) [8]. Hence, demonstration of secreted and functional Fm PEP from LAB would be a significant step for the prospective treatment of celiac disease.

To accomplish these goals, tools that enable efficient recombinant protein expression in LAB, are essential. Although genomics, metabolic pathways and genetic toolboxes, consisting of cloning vectors, mutagenesis systems [9], have been well developed and studied, tools for engineering the $\mathrm{LAB}$ recombinant protein cassette for protein secretion focus mainly on vector [10-12], strain optimisation [13] and signal peptides [14-16]. The latter focus mainly on screening and mutagenesis of signal peptides, in addition to the commonly used USP45, to create signal peptide libraries [14, 17]. Less intensively investigated is the development of secretion propeptides for secretion efficiencies and thus yield enhancement [9]. The main propeptide currently in use, LEISSTCDA, was first created for secretion of Staphylococcus aureus nuclease and then subsequently utilized for other recombinant proteins in LAB. Although, LEISSTCDA has been used in various studies to increase secretion yields [18], it is not an universal enhancer of heterologous secretion, for example, in the case of an anti-freeze protein, a reduction in secretion was observed instead [19]. Further mutagenesis within LEISSCTDA did not yield improved propeptides [20]. This suggests a larger secretion propeptide library would be critical in further optimizing secretion yields of different recombinant proteins in LAB.

In this study, we exploited advancement in genomics and availability of sequenced LAB genomes assemblies to mine for secretion propeptides. Three unique propeptide sequences were identified and they were evaluated in parallel with commonly used LEISSCTDA on secretion of two recombinant proteins in Lactococcus lactis. The newly mined propeptides were first characterized using secretion of recombinant $E$. coli thioredoxin (TRX), which has been used extensively as a solubility partner for recombinant protein expression in $E$. coli $[21,22]$ and more recently, utilized as an intracellular solubility partner in L. lactis [23]. Next they were then applied for the secretion of $78 \mathrm{kDa} F \mathrm{P}$ PEP. This is the first instance of Fm PEP secretion and its optimization in L. lactis.

\section{Results}

\section{Mining of propeptides}

We first chose a reference signal peptide, the naturally occurring signal peptide from $L$. lactis secreted protein of unknown function (USP45 SP). Besides being the currently most utilized secretion signal peptide for L. lactis, USP45 SP has also been shown to be more efficient over other natural signal peptides (SP310 [24]) or mutated libraries (USP45MT11 [14], SP310mut2 [17]). To mine for secretion propeptides, the amino acid sequence of USP45 SP (Accession Code: ABY84357) was used to blast against 109 deposited assemblies of Lactococcus species (accessed October 18, 2016). From the BlastP search, three propeptide sequences, which were most representative of the results, were identified (Fig. 1a). The estimated frequency of these propeptides from the BLAST search (not accounting for highly identical sequences); 


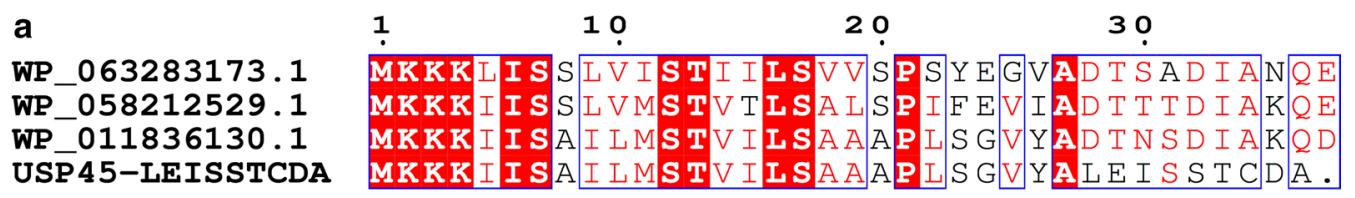

b

\begin{tabular}{cccc}
\hline Label & Sequence & Isoelectric point $(\mathbf{p H})$ & Net charge at $\mathbf{p H ~ 7}$ \\
\hline PP1 & DTNSDIAKQD & 3.41 & -2 \\
PP2 & DTTTDIAKQE & 3.54 & -2 \\
PP3 & DTSADIANQE & 0.59 & -3 \\
PC & LEISSTCDA & 0.62 & -2
\end{tabular}

Fig. 1 Mining of propeptides from sequenced Lactococcus genome assemblies. a Alignment of native Lactococcus proteins with USP45-LEISSTCDA sequence. Alignment was created in ESPript 3.0 [31]. b Comparison of isoelectric points and net charges of the three propeptides (PP1-PP3) and positive control LEISSTCDA (PC) propeptide

PP1:PP2:PP3 are 59:3:9. The isoelectric point of these propeptides ranged from 0.6 to 3.5 , compared to 0.6 for our positive control propeptide LEISSTCDA. All three propeptides have a net charge of -2 to -3 at $\mathrm{pH}$ 7 (Fig. 1b). The negative charges of the propeptides are contributed by the multiple aspartic acid and glutamic acid residues in the sequences. These observations also correspond to the previous finding that negative charge of LEISSTCDA plays a significant role in increasing secretion efficiencies [18]. Henceforth for simplicity, the three data-mined propeptides will be labelled as PP1PP3 (Fig. 1b).

\section{TRX secretion and optimization}

As an initial evaluation of these propeptides, we utilized the soluble $15 \mathrm{kDa} E$. coli TRX as our reporter protein. The glycine-serine linked protein expression cassette (Fig. 2a) consisted of USP45 SP, followed by the propeptide of interest, the N-terminal of the codon-optimized TRX gene cassette. The C-terminal of the gene cassette consisted of a glycine-serine-alanine (GSGSGAAA) linker before a TEV cleavage site (ENLYFQG) and a his6tag $(\mathrm{HHHHHH).} \mathrm{In} \mathrm{our} \mathrm{control} \mathrm{expression} \mathrm{cassette,} \mathrm{there}$ are no propeptide and only one GS linker between USP45 SP and TRX. The protein expression cassette was introduced into nisin-inducible pNZ8148 via DNA assembly.

The final constructs were transformed into NZ9000 and grown at $30{ }^{\circ} \mathrm{C}$. Induction of the culture proceed at $\mathrm{OD}_{600}=0.5$ with $10 \mathrm{ng} / \mathrm{mL}$ nisin (Fig. 2b). After $3 \mathrm{~h}$ of expression, his-tagged proteins of the expected sizes (15-19 kDa) were observed (Fig. 2c). Bands on the Western blot, corresponding to full length (17 kDa) USP45-TRX and its truncated (15 kDa) TRX, were observed for USP45-TRX in intracellular and secreted fractions respectively. Similarly, for
USP45-propeptide-TRX constructs, bands corresponding to full length $(19 \mathrm{kDa})$ USP45-propeptide TRX and truncated $(16 \mathrm{kDa})$ propeptide-TRX were also observed in intracellular and extracellular fractions respectively. From the observed sizes of the TRX constructs, truncation of the secreted protein is predicted to occur between the signal peptide and propeptides. This is as predicted with SignalP 4.1 [25].

With USP45 SP only, a $27 \%$ secretion efficiency for TRX was observed. Whilst upon insertion of propeptides, a maximum of 1.7 -fold improvement in secretion efficiency (LEISSTCDA, 47\%, Fig. 2c) was observed. With increased secretion efficiencies, there are also corresponding 1.5-2.3-folds increases in both volumetric and specific secretion yields for propeptide containing constructs, compared to without propeptide (Fig. 2c). Overall, PP1-3 were observed to enhance both secretion efficiencies and yields like LEISSTCDA. However, for TRX, the positive control LEISSTCDA still yielded the highest amount of secreted TRX, among the propeptides.

\section{Expression and secretion of functional Fm PEP}

Next, we examine effects of PP1-3 on the secretion of Fm PEP. The glycine-serine linked protein expression cassette consisted of USP45 SP, followed by the propeptide of interest, the codon-optimized Fm PEP gene cassette and a his6-tag at the C-terminal (Fig. 3a). In our control expression cassette, there are no propeptide and only one GS linker between USP45 SP and Fm PEP. Again, the protein expression cassette was introduced into nisin-inducible pNZ8148 via DNA assembly.

After nisin induction of NZ9000-transformed strains at $30{ }^{\circ} \mathrm{C}$ for $3 \mathrm{~h}$ (Fig. 3b), both cell lysate and media were analysed by Western blot analysis (Fig. 3c, d). Bands at $75 \mathrm{kDa}$ corresponding to the size of Fm PEP were 
a

C
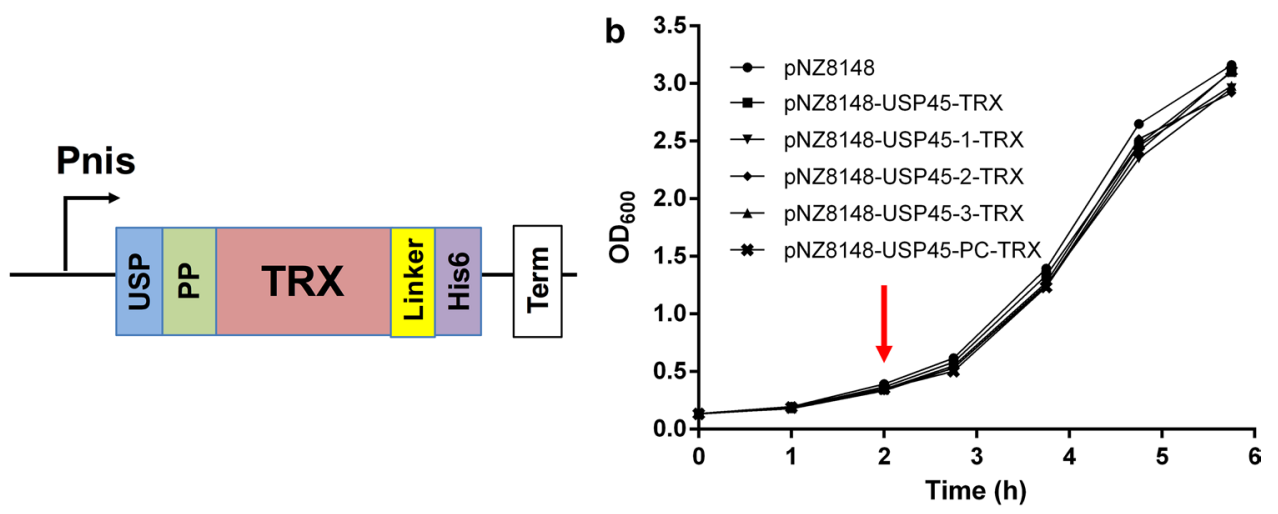

$\frac{\text { No PP }}{\text { C S PP 1 }} \frac{\text { PP 2 }}{\text { C S }} \frac{\text { PP 3 }}{\text { S S }} \frac{P C}{C S}$

$20 \mathrm{kDa}$

$15 \mathrm{kDa}$

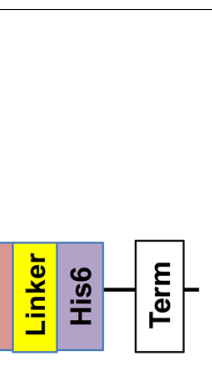

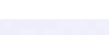

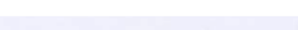

.

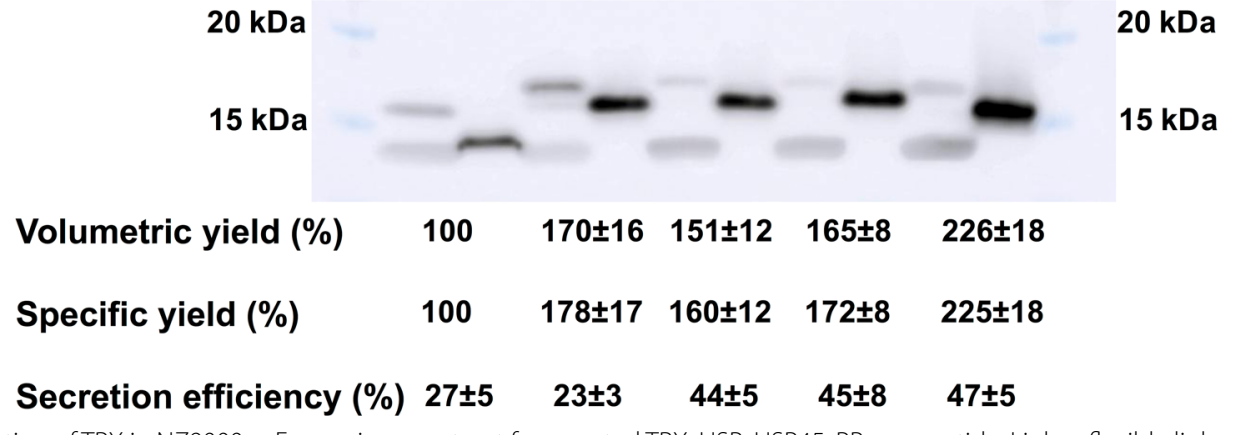

Fig. 2 Secretion of TRX in NZ9000. a Expression construct for secreted TRX, USP: USP45, PP: propeptide, Linker: flexible linker with TEV cleavage site, His6: HisTag, Term: terminator. b Growth curves for pNZ8148 vector only, USP45-TRX, USP45-PP1-, -PP2-, -PP3-, -PC-TRX. Induction is indicated by a red arrow. c Representative Western blot of cell lysate (C) and secreted (S) fractions. Cell lysate and secreted fractions were concentrated 3 and 25 times respectively and $2 \mu \mathrm{L}$ of each was loaded onto the gel. The lowest conserved band observed in the cell lysate fraction is a non-specific binding artefact (Additional file 1: Figure S1). \% protein yields, with reference to USP45-TRX, and secretion efficiencies of the various TRX constructs are given below. These were calculated based on densitometry and technical triplicates

observed in both cell lysate and media fractions (Fig. 3c, d). Two closely migrated bands, observed near $75 \mathrm{kDa}$, are predicted to be full length constructs $(84$ and $83 \mathrm{kDa}$ for with and without propeptide respectively) and truncated Fm PEP (81 and $80 \mathrm{kDa}$ for with and without propeptide respectively) (Fig. 3c, d). Bands of the truncated Fm PEPs were observed in the soluble intracellular fraction, suggesting that the precursors are undergoing cleavage within the cells. In the intracellular fractions, solubility of the proteins range from 46 to $68 \%$ of the total intracellular proteins, and from our enzymatic assays, the soluble intracellular proteins were found to be active (Additional file 1: Figure S2). A general increase in volumetric secretion yields (1.4-2.2-folds) was observed with the introduction of the propeptides into the Fm PEP expression cassette (Fig. 3e). When normalized to optical density, increases in specific secretion yields are 2.3, 1.7, 2.8 and 1.3-folds for PP1, PP2, PP3 and LEISSTCDA respectively. The higher specific yield of PP3 is a result of significant reduced growth of the host cell after nisin induction (Fig. 3b).
Comparison of PEP activities in the media fractions also displayed a similar enhancement trend to that of the secretion yields (Fig. 3e). This also suggest that there are minimal effects on Fm PEP activity from insertion of different highly negative charged propeptides at the N-terminus. Comparison between propeptides also indicated that a different preference of propeptide was demonstrated by Fm PEP compared to TRX. For Fm PEP, PP1 produced the best volumetric secretion yield and activity (2.2-fold) whilst the positive control LEISSTCDA only managed a 1.4-fold increase in yield and activity.

Although we demonstrated secretion of active Fm PEP in L. lactis, the secretion efficiencies for Fm PEP (estimated $0.9-1.6 \%)$ is still significantly lower than that of TRX (23-47\%). This could be attributed to the higher solubility and lower molecular weight of TRX compared to Fm PEP. Strikingly, although folding is not expected to take place with the presence of the signal peptide intracellularly, the cell lysate was found to contain soluble, cleaved and functional Fm PEP proteins (Fig. 3d, Additional file 1: Figure S2). These observations suggest that 


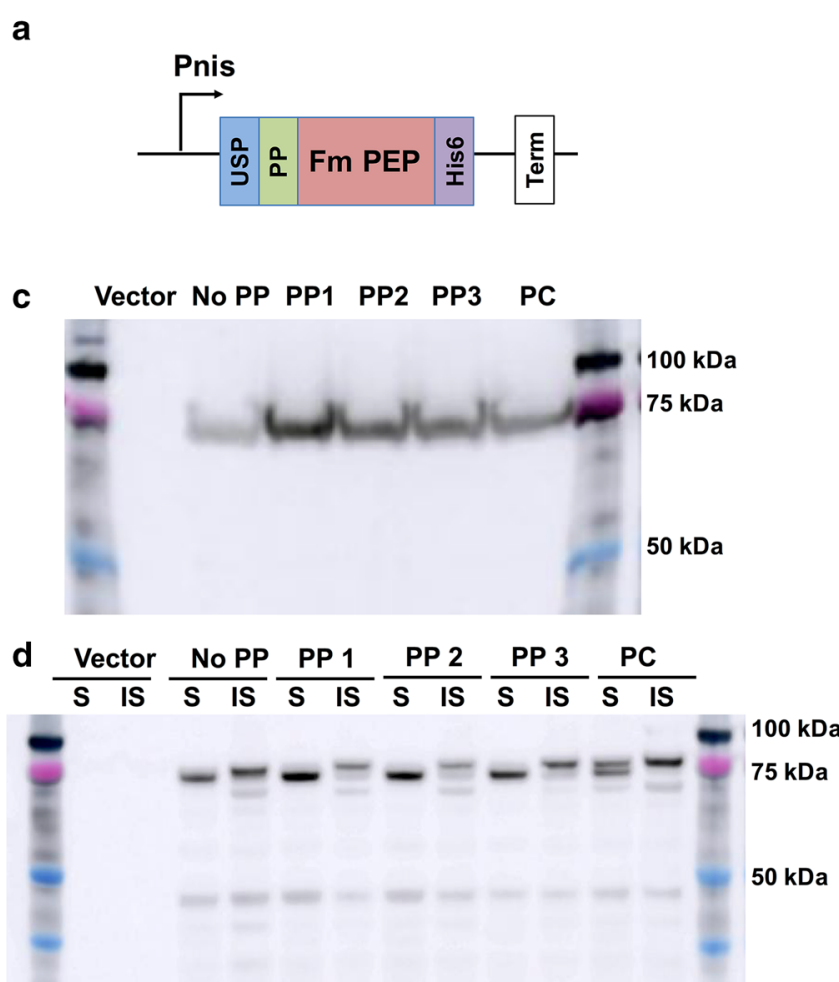

Solubility (\%) $53 \pm 6 \quad 66 \pm 2 \quad 68 \pm 4 \quad 59 \pm 5 \quad 46 \pm 11$
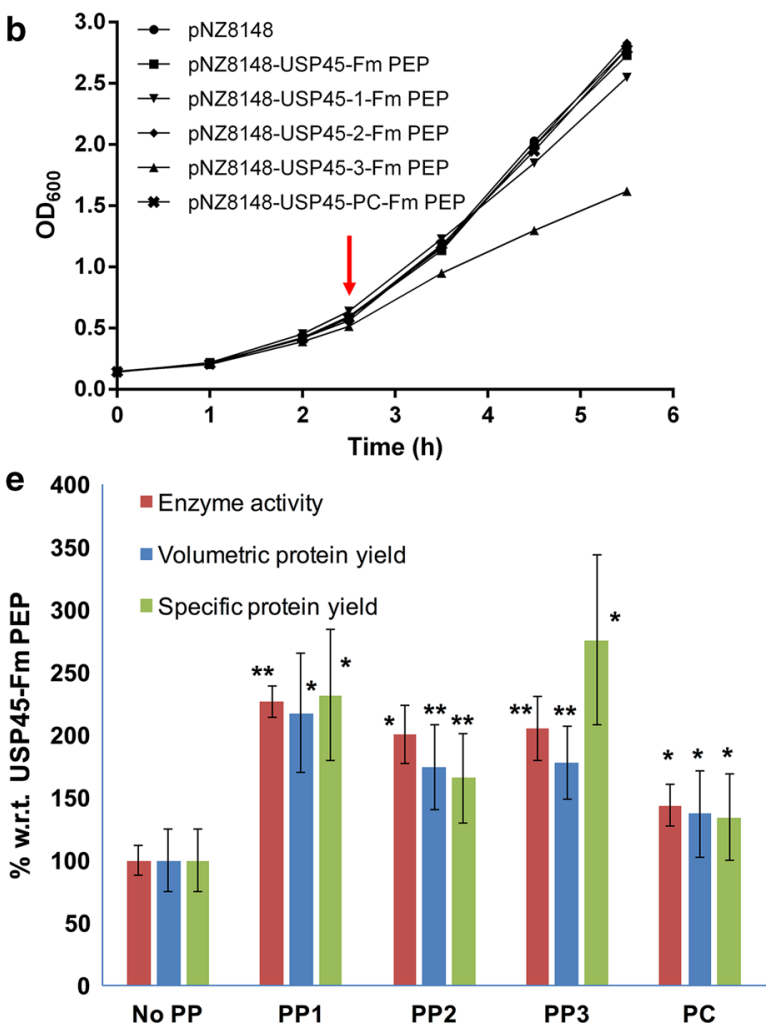

Fig. 3 Secretion of Fm PEP in NZ9000. a Expression construct for secreted Fm PEP, USP: USP45, PP: propeptide, His6: HisTag, Term: terminator. b Growth curves for pNZ8148 vector only, USP45-FmPEP, USP45-PP1-,-PP2-, -PP3-, -PC-FmPEP. Induction is indicated by a red arrow. c Comparison of media fractions on a representative Western blot. Vector refers to expression of an empty pNZ8148 vector. d Representative Western blot comparison of soluble (S) and insoluble (IS) fractions in the cell lysate. Vector refers to expression of an empty pNZ8148 vector. Cell lysate and secreted fractions were concentrated 3 and 25 times respectively and $2 \mu \mathrm{L}$ of each was loaded onto the gel. e \% secretion yields and secretion efficiencies for the various constructs with respect to USP45-Fm PEP. Secretion protein yields are calculated based on densitometry. Enzyme activities were calculated based on Z-gly-pro-4-nitroanilide assay. Biological and technical triplicates were performed for these experiments, significant at ${ }^{*} p<0.05$,

**p $<0.01$. Results are summarized in Additional file 1:Table S1

further design optimization could be used to reduce intracellular cleavage and in turn, increase secretion efficiencies.

In examination of growth rates, slower growth were observed in PP1 and PP3 for Fm PEP, especially so for the latter. This decrease in growth rates after induction could be contributed to inability of the cells to handle the additional stress of protein secretion [26, 27]. This also suggests that higher yield can be achieved by optimization of strains and systems for secretion [10-13].

\section{Discussion}

In this study, 3 naturally occurring propeptides were examined in addition to the widely utilized synthetic propeptide LEISSTCDA. The set of 4 propeptides were evaluated using two different recombinant proteins, where the ability to increase secretion yields and efficiencies were demonstrated for all 4 highly negative charged propeptides. However, from characterisation of 2 proteins, it was shown that the optimal propeptide for each protein with USP45 SP is not the same. With TRX, the LEISSTCDA produced the highest secretion yields, although similar increases in secretion efficiencies were observed for PP3, PP2 and LEISSTCDA. With Fm PEP, the highest volumetric yield and secretion efficiency were obtained by PP1. These observations emphasize once again that success of heterologous protein expression and secretion are hard to predict rationally. Interactions of the signal peptides, propeptides and protein of interest, including balancing of translation, secretion and folding pathways, are all contributors to its final secretion yield and efficiency [9]. Subsequently, this highlights the importance of a well-characterized and tested toolbox for rapid screening and optimization of the recombinant protein secretion in LAB.

In our examination of the newly-mined propeptides, we have also demonstrated secretion of functional Fm PEP. Previously, Fm PEP have been examined as a 
potential PEP candidate for celiac disease treatment, where the enzyme has been shown to be resistant to the acid and protease-rich environment of the small intestine and also activity towards the inflammatory proline-rich prolamins from wheat, barley and rye [28, 29]. With the usage of PP1, volumetric secretion yield from L. lactis can be further increased 2.2-fold. As with the Mx PEP secretion in L. casei [7], we expect that this secretion can be further improved by utilization of $\mathrm{pH}$ controlled fermentation and carbon source. To eventually utilize the Fm PEP secretion for mucosal delivery of proteins, GRAS status of LAB strain and stable chromosomal integration of the gene have to be accomplished.

\section{Conclusion}

From deposited genomics data, we identified three new naturally occurring propeptide candidates for secretion enhancement. Through characterization of these three propeptides, along with a positive control LEISSTCDA, we were able to demonstrate that these propeptides are not only comparable to LEISSTCDA as a secretion enhancement but also in the optimization of Fm PEP, they outperformed LEISSTCDA. Depending on the combination of protein of interest and propeptides, 1.4-2.3-folds increase in volumetric secretion yields were observed. In this work, we have also demonstrated, for the first time, expression and secretion of functional Fm PEP in L. lactis, subsequently, further optimization would be required to fully utilize the potential of $L$. lactis as a delivery and secretion vector.

\section{Methods}

\section{Bacteria, LAB strains, vector and culture media}

NZ9000 strain and pNZ8148 plasmid of NICE ${ }^{\circledR}$ Expression System were obtained from Boca Scientific. Genes were synthesized by Integrated DNA Technologies. Growth media, M17 and GM17, were obtained from BD Biosciences (USA).

\section{Protein cassette construction on pNZ8148}

Genes were codon-optimized using Integrated DNA Technologies' codon optimization tool for L. lactis cremoris. The codon-optimized genes were amplified from synthesized Gblocks ${ }^{\circledR}$ gene fragments (Integrated DNA Technologies) using the KOD-Xtreme kit (Merck). The PCR products were $D p n \mathrm{I}$-treated for at least $2 \mathrm{~h}$ and then cleaned up and concentrated using the DNA clean and concentrator kit (Zymo research). pNZ8148 were digested with restriction enzymes for at least $5 \mathrm{~h}$ at $37^{\circ} \mathrm{C}$. They were then incubated with thermosensitive alkaline phosphatase TSAP (Promega) for $2 \mathrm{~h}$ before they were cleaned and concentrated. The genes were then assembled into the vectors using Gibson assembly mix (New
England Biolabs) for $1 \mathrm{~h}$ at $50{ }^{\circ} \mathrm{C} .2 \mu \mathrm{L}$ of the Gibson assembly mixture was added into $50 \mu \mathrm{L}$ of electrocompetent NZ9000 cells and electroporated using $0.1 \mathrm{~cm}$ cuvette at $1800 \mathrm{~V} .1 \mathrm{~mL}$ of GM17 media with $20 \mathrm{mM}$ $\mathrm{MgCl}_{2}$ and $2 \mathrm{mM} \mathrm{CaCl}$ was added immediately after electroporation. The cuvette was kept on ice for $5 \mathrm{~min}$ before incubating the cells at $30^{\circ} \mathrm{C}$ for $1-2 \mathrm{~h}$. The cells were centrifuged and resuspended in $100 \mu \mathrm{L}$ of media before they were plated out on M17 with $0.5 \%$ glucose (GM17) agar with $10 \mu \mathrm{g} / \mathrm{mL}$ chloramphenicol and incubated at $30{ }^{\circ} \mathrm{C}$ for 2 days. Colonies were screened for the correct construct before isolation and sequencing of the plasmids were performed.

\section{Protein expression and cell lysate fraction extraction}

$2 \%$ of overnight culture was inoculated into $50 \mathrm{~mL}$ of fresh GM17 media. The culture was grown statically at $30{ }^{\circ} \mathrm{C}$ to $\mathrm{OD}_{600} 0.5$ before inducing with $10 \mathrm{ng} / \mathrm{mL}$ nisin. The culture, supernatant and cell pellet, was harvested $3 \mathrm{~h}$ after nisin induction by centrifugation at $4600 \mathrm{rpm}$ for $10 \mathrm{~min}$. The cell pellet was washed and re-suspended in $300 \mu \mathrm{L}$ of Lysis Equilibration Wash buffer (LEW buffer: $50 \mathrm{mM}$ $\mathrm{NaH}_{2} \mathrm{PO}_{4}, 300 \mathrm{mM} \mathrm{NaCl}, \mathrm{pH}$ 8.0). $1 \mathrm{mg} / \mathrm{mL}$ lysozyme and $50 \mathrm{U} / \mathrm{mL}$ mutanolysin were added to the cell suspensions and the cell suspensions were incubated at $30{ }^{\circ} \mathrm{C}$ for $30 \mathrm{~min}$. The cell suspensions were kept on ice and sonicated 4 times for $10 \mathrm{~s}$ at $10 \mathrm{~s}$ interval using Microson XL2000 sonicator at $22.5 \mathrm{kHz}$. The cell lysate was spun down at $10,000 \mathrm{~g}$ for $30 \mathrm{~min}$ at $4{ }^{\circ} \mathrm{C}$ and the supernatant was removed as the soluble fraction. The remaining pellets were washed and re-suspended in denaturing buffer (50 $\mathrm{mM} \mathrm{NaH}_{2} \mathrm{PO}_{4}, 300 \mathrm{mM} \mathrm{NaCl}, 8 \mathrm{M}$ Urea, $\mathrm{pH} \mathrm{8.0)}$ and spun down $(10,000 \mathrm{~g}, 20 \mathrm{~min})$ to obtain the insoluble fraction. Biological triplicates were performed.

\section{Secretion fraction}

$30 \mathrm{~mL}$ of the media fraction after $3 \mathrm{~h}$ of induction was removed. This was buffer exchanged and concentrated to $200 \mu \mathrm{L}$ at $4{ }^{\circ} \mathrm{C}$ using an Amicon ultra centrifugal filter with cold $10 \mathrm{mM}$ sodium phosphate buffer, $\mathrm{pH}$ 7.0. To ensure that cell lysis of NZ9000 strains were insignificant during production [13], we compared the genomic DNA content in culture media of intact cells to completely lysed cells at the point of harvest, using quantitative PCR with $L$. lactis specific primers for the housekeeping tuf gene as described [30]. Based on this comparison, cell lysis was predicted to be kept to under $0.1 \%$.

\section{Immunoblotting}

Protein samples were analysed on NuPAGE 4-12 or $12 \%$ Bis-Tris Gel (Life Technologies). The proteins were then transferred on to a nitrocellulose membrane using semi-dry method (Trans-Blot; Biorad) at $20 \mathrm{~V}$ for $20 \mathrm{~min}$. 
The membrane was washed with PBST (PBS with 0.1\% Tween) and then blocked using 5\% w/v non-fat dry milk in PBST (Biorad) for $1 \mathrm{~h}$ at room temperature and then washed with PBST. 1:10,000 Anti-His Antibodies (Millipore) in Signal Enhancer HIKARI Solution B (Nacalai Tesque) was added to the membrane and incubated at $4{ }^{\circ} \mathrm{C}$ overnight before detecting with Clarity Western ECL Blotting Substrates (Biorad) using manufacturer's protocol. Densitometry were performed using ImageJ. Protein yields were calculated with respect to the no-propeptidecontaining-USP45 construct, using secreted proteins per culture volume. Secretion efficiencies were calculated as the secreted protein over total proteins produced.

\section{Z-gly-pro-4-nitroanilide assay}

$2 \mu \mathrm{L}$ of the concentrated secreted fraction was added to a mixture containing $5 \mu \mathrm{L}$ of $2 \mathrm{mM} \mathrm{Z}$-gly-pro-4-nitroanilide (in 1,4-dioxane) and $100 \mu \mathrm{L}$ of $10 \mathrm{mM}$ sodium phosphate buffer, $\mathrm{pH}$ 7.0. The release of $p$-nitroanilide was measured at $410 \mathrm{~nm}$ using technical triplicates.

\section{Additional file}

Additional file 1: Figure S1. TRX secretion. Figure S2. Enzymatic activity of a representative set of intracellular fractions for pNZ8148 vector only, USP45-FmPEP, USP45-PP1-, -PP2-, -PP3-, -PC-FmPEP. Table S1. Comparison of Fm PEP constructs.

\section{Abbreviations}

LAB: lactic acid bacteria; GRAS: generally regarded as safe; SP: signal peptide; TRX: thioredoxin; Fm PEP: Flavobacterium meningosepticum prolyl endopeptidase; Mx PEP: Myxococcus xanthus prolyl endopeptidase.

\section{Authors' contributions}

ODS and FTW contributed to conception and design of the study. FTW drafted the manuscript and ODS edited it. Cloning was performed by LPY and TLL. Culturing and Western blot were performed by LPY. TLL performed the enzymatic assays and secretion clean-up. All analyzed and interpreted the data. All authors read and approved the final manuscript.

\section{Acknowledgements}

We like to acknowledge Sydney Brenner for his support. We thank Chong Hui Koh for her assistance in the fermentation work.

\section{Competing interests}

The authors declare that they have no competing interests.

\section{Availability of data and materials}

All data generated or analysed during this study are included in this published article (and its Additional file).

\section{Consent for publication \\ Not applicable.}

Ethics approval and consent to participate

Not applicable.

\section{Funding}

This project is funded by the Joint Council Office (JCO), A*STAR. LPY and TLL are funded by JCO, A*STAR (JCO-1431AFG126).

\section{Publisher's Note}

Springer Nature remains neutral with regard to jurisdictional claims in published maps and institutional affiliations.

Received: 28 March 2017 Accepted: 28 November 2017

Published online: 05 December 2017

\section{References}

1. Pfeiler EA, Klaenhammer TR. The genomics of lactic acid bacteria. Trends Microbiol. 2007; 15:546-53.

2. Garcia-Fruitos E. Lactic acid bacteria: a promising alternative for recombinant protein production. Microb Cell Fact. 2012;11:157.

3. Arques JL, Rodriguez E, Langa S, Landete JM, Medina M. Antimicrobial activity of lactic acid bacteria in dairy products and gut: effect on pathogens. Biomed Res Int. 2015;2015:584183.

4. Wiese M, Eljaszewicz A, Helmin-Basa A, Andryszczyk M, Motyl I, Wieczynska J, Gackowska L, Kubiszewska I, Januszewska M, Michalkiewicz J. Lactic acid bacteria strains exert immunostimulatory effect on H. pylori-induced dendritic cells. J Immunol Res. 2015;2015:106743.

5. Pontes DS, de Azeyedo MSP, Chatel JM, Langella P, Azeyedo V, Miyoshi A. Lactococcus lactis as a live vector: heterologous protein production and DNA delivery systems. Protein Expr Purif. 2011;79:165-75.

6. Makharia GK. Current and emerging therapy for celiac disease. Front Med. 2014;1:6.

7. Alvarez-Sieiro P, Martin MC, Redruello B, del Rio B, Ladero V, Palanski BA, Khosla C, Fernandez M, Alvarez MA. Generation of food-grade recombinant Lactobacillus casei delivering Myxococcus xanthus prolyl endopeptidase. Appl Microbiol Biotechnol. 2014;98:6689-700.

8. Fuhrmann $\mathrm{G}$, Leroux JC. In vivo fluorescence imaging of exogenous enzyme activity in the gastrointestinal tract. Proc Natl Acad Sci USA. 2011;108:9032-7.

9. Le Loir Y, Azevedo V, Oliveira SC, Freitas DA, Miyoshi A, BermudezHumaran LG, Nouaille S, Ribeiro LA, Leclercq S, Gabriel JE, et al. Protein secretion in Lactococcus lactis: an efficient way to increase the overall heterologous protein production. Microb Cell Fact. 2005;4:2.

10. Mierau I, Kleerebezem M. 10 years of the nisin-controlled gene expression system (NICE) in Lactococcus lactis. Appl Microbiol Biotechnol. 2005;68:705-17.

11. Karlskås IL, Maudal K, Axelsson L, Rud I, Eijsink VG, Mathiesen G. Heterologous protein secretion in Lactobacilli with modified pSIP vectors. PLoS ONE. 2014;9:e91125.

12. Neef J, Milder FJ, Koedijk DG, Klaassens M, Heezius EC, van Strijp JA, Otta A, Becher D, van Dijl JM, Buist G. Versatile vector suite for the extracytoplasmic production and purification of heterologous His-tagged proteins in Lactococcus lactis. Appl Microbiol Biotechnol. 2015;99:9037-48.

13. Neef J, Koedijk DG, Bosma T, van Dijl JM, Buist G. Efficient production of secreted staphylococcal antigens in a non-lysing and proteolytically reduced Lactococcus lactis strain. Appl Microbiol Biotechnol. 2014:98:10131-41.

14. Ng DTW, Sarkar CA. Engineering signal peptides for enhanced protein secretion from Lactococcus lactis. Appl Environ Microb. 2013;79:347-56.

15. Samazan F, Rokbi B, Seguin D, Telles F, Gautier V, Richarme G, Chevret D, Varela PF, Velours C, Poquet I. Production, secretion and purification of a correctly folded staphylococcal antigen in Lactococcus lactis. Microb Cell Fact. 2015;14:104

16. Morello E, Bermúdez-Humarán LG, Llull D, Solé V, Miraglio N, Langella P, Poquet I. Lactococcus lactis, an efficient cell factory for recombinant protein production and secretion. J Mol Microbiol Biotechnol. 2008;14:48-58.

17. Ravn P, Arnau J, Madsen SM, Vrang A, Israelsen H. Optimization of signal peptide SP310 for heterologous protein production in Lactococcus lactis. Microbiology. 2003;149:2193-201.

18. Le Loir Y, Gruss A, Ehrlich SD, Langella P. A nine-residue synthetic propeptide enhances secretion efficiency of heterologous proteins in Lactococcus lactis. J Bacteriol. 1998;180:1895-903.

19. Yeh CM, Huang XH, Sue CW. Functional secretion of a type 1 antifreeze protein analogue by optimization of promoter, signal peptide, prosequence, and terminator in Lactococcus lactis. J Agric Food Chem. 2008;56:8442-50. 
20. Le Loir Y, Nouaille S, Commissaire J, Bretigny L, Gruss A, Langella P. Signal peptide and propeptide optimization for heterologous protein secretion in Lactococcus lactis. Appl Environ Microb. 2001;67:4119-27.

21. Gopal GJ, Kumar A. Strategies for the production of recombinant protein in Escherichia coli. Protein J. 2013;32:419-25.

22. Lavallie ER, Diblasio EA, Kovacic S, Grant KL, Schendel PF, McCoy JM. A thioredoxin gene expression system that circumvents inclusion body formation in the E. coli cytoplasm. Biotechnology (NY). 1993;11:187-93.

23. Douillard FP, O'Connell-Motherway M, Cambillau C, van Sinderen D. Expanding the molecular toolbox for Lactococcus lactis: construction of an inducible thioredoxin gene fusion expression system. Microb Cell Fact. 2011;10:66.

24. Ravn P, Arnau J, Madsen SM, Vrang A, Israelsen $\mathrm{H}$. The development of TnNuc and its use for the isolation of novel secretion signals in Lactococ cus lactis. Gene. 2000;242:347-56.

25. Petersen TN, Brunak S, von Heijne G, Nielsen H. SignalP 4.0: discriminating signal peptides from transmembrane regions. Nat Methods. 2011;8:785-6.
26. Bolhuis A, Broekhuizen CP, Sorokin A, van Roosmalen ML, Venema G, Bron S, Quax WJ, van Dijl JM. SecDF of Bacillus subtilis, a molecular Siamese twin required for the efficient secretion of proteins. J Biol Chem. 1998;273:21217-24.

27. Trémillon N, Issaly N, Mozo J, Duvignau T, Ginisty H, Devic E, Poquet I. Production and purification of Staphylococcal nuclease in Lactococcus lactis using a new expression-secretion system and a pH-regulated minireactor. Microb Cell Fact. 2010;9:37.

28. Gass J, Bethune MT, Siegel M, Spencer A, Khosla C. Combination enzyme therapy for gastric digestion of dietary gluten in patients with celiac sprue. Gastroenterology. 2007;133:472-80.

29. Shan L, Martin T, Sollid LM, Gray GM, Khosla C. Comparative biochemical analysis of three bacterial prolyl endopeptidases: implications for coeliac sprue. Biochem J. 2004;383:311-8.

30. Ruggirello M, Dolci P, Cocolin L. Detection and viability of Lactococcus lactis throughout cheese ripening. PLoS ONE. 2014;9(12):e114280.

31. Robert $X$, Gouet P. Deciphering key features in protein structures with the new ENDscript server. Nucleic Acids Res. 2014:42:W320-4.

\section{Submit your next manuscript to BioMed Central and we will help you at every step:}

- We accept pre-submission inquiries

- Our selector tool helps you to find the most relevant journal

- We provide round the clock customer support

- Convenient online submission

- Thorough peer review

- Inclusion in PubMed and all major indexing services

- Maximum visibility for your research

Submit your manuscript at www.biomedcentral com/submit 